\title{
Advances in Psychiatric Treatment for trainees?
}

\author{
Rebecca Slinn
}

The journal Advances in Psychiatric Treatment (APT) was first published in 1994 as a major tool in the College's programme of Continuing Professional Development (CPD). It aims specifically to act as a user-friendly journal to aid the CPD of consultant psychiatrists in the UK and Ireland. The emphasis has been on a clear, informative style that is easy to read, with plenty of headings, summary boxes and tables.

It was anticipated that $A P T$ might appeal to a wider audience and that has proven to be true, with subscriptions from abroad and a readership among trainees. Indeed, it would be odd for the journal suddenly to become relevant to psychiatrists at the moment of appointment to a consultant job. While the process of career development has a very clear cut-off between a training grade and a consultant appointment, the process of learning does not. Thus, although the journal would not be the first thing to recommend to a brand-new trainee, as it assumes quite a level of psychiatric knowledge in its readers, it could soon start to play a useful role. An informal survey among trainee colleagues suggested that many start to use it prior to the Membership examination, frequently at the suggestion of their consultants. They then continue to read it during their post-Membership training.

A preoccupation of life as a basic specialist trainee is the MRCPsych Examination and much reading therefore is aimed at preparation for this. APT may fit into this framework of reading as a useful adjunct to the basic textbooks, less daunting than a pile of original papers and just as well referenced. The articles written on the physical and psychological aspects of treatment, as well as the sub-specialities, are probably most useful at this stage for their summary of knowledge in a particular area and the self-assessing multiple choice questions at the end. Updated collections of these articles are published in the series Recent Topics from Advances in Psychiatric Treatment (Lee, 1998, 1999). Some articles have been written in tandem with a commentary article with the purpose of highlighting areas of controversy. These give ideas for "Discuss..."-type essay questions. For examination candidates, an additional bonus is that they may be fairly confident that their examiners are reading the same articles.

Post-Membership trainees have different requirements and responsibilities. The emphasis of professional reading changes from being predominantly examination-oriented to furthering specialist knowledge and attaining the 'exit' skills of training while retaining a good general knowledge. Once again, $A P T$ can be a part of this reading framework, not only with regard to developing good habits in updating general knowledge, but also in developing non-clinical skills. In becoming a specialist registrar or lecturer, it is necessary to become more active in teaching both basic specialist trainees and undergraduates. Articles on medical education and supervision such as those in $A P T^{\prime}$ 's 'teaching and learning series' therefore become more valuable. The reality of becoming a consultant is looming and articles on service development, management and leadership have more immediate meaning, both outlining the skills to be attained and providing subjects for discussion at consultant interview panels.

In highlighting the strengths of APT for trainees, there has been a danger of sounding like an advertisement - uncritical and with evangelistic

Rebecca Slinn is Specialist Registrar in Old Age and General Adult Psychiatry in the Department of Psychiatry at Southmead Hospital, Bristol and Vice Chair of the Royal College of Psychiatrists' Collegiate Trainees' Committee. 
zeal. There is no claim that $A P T$ is the last word in reading for trainees at any stage, or that it is not in fact perfectly possible to pass the examination and attain a consultant job without having turned the cover. The important point is that it is well worth trainees considering it as an additional weapon in their armoury for their ongoing learning and career development.

\section{References}

Lee, A. (ed) (1998) Acute Psychosis, Schizophrenia and Comorbid Disorders. Recent Topics from Advances in Psychiatric Treatment, Vol. 1. London: Gaskell.

- (ed) (1999) Affective and Non-Psychotic Disorders. Recent

Topics from Advances in Psychiatric Treatment, Vol. 2. London: Gaskell.

\section{New from Gaskell}

\section{Psychosis: Psychological Approaches and their Effectiveness Putting Psychotherapies at the Centre of Treatment}

\section{Edited by Brian Martindale, Anthony Bateman, Michael Crowe \& Frank Margison}

This is a most timely book as there is increasing recognition by both professionals and users (and also service planners) that psychological approaches for people with psychotic conditions can be effective, and indeed, are often much sought after by users and their families. However, these were rarely considered and often disparaged in the ascendancy of the 'decade of the brain'. The book updates psychiatrists, psychologists and nurses in a range of psychological therapies that should be available in every modern mental health service. It both outlines the approaches and provides or reviews evidence for their effectiveness.

The authors are selected expert clinicians and researchers from around the globe who describe in clear language the differing contexts, aims and methods of the psychological treatment interventions and evidence for their effectiveness.

There is a wide-ranging introduction then a section based on cognitive approaches, then another on family, group and psychosocial approaches, followed by a psychoanalytic approach. The penultimate section describes the integration of a range of these approaches used in early interventions, designed to improve the chances of full recovery in the community and minimise chronic disability. The authors of this section are Scandinavian where these approaches are increasingly widely practiced. Finally, there is a comprehensive overview from Australia that gives an encouraging vision of modern mental health services for those vulnerable to severe mental disturbance and also valuable pointers to further research likely to be fruitful.

May 2000, £25.00, paperback, ISBN 1901242498

Booksales, Royal College of Psychiatrists, 17 Belgrave Square, London SW1X 8PG. Tel: +44 (0)20 72352351 ext. 146; Fax: +44 (0)20 72451231 The latest information on College publications is on the Internet at http://www.rcpsych.ac.uk 